\title{
A Química é Quem Mais Ordena*
}

\author{
Jorge Calado \\ Centro de Química Estrutural, Instituto Superior Técnico, UTL \\ jcalado@ist.utl.pt
}

\begin{abstract}
A Química quer saber de que é que são feitas as coisas, e o que acontece quando pomos as coisas em contacto umas com as outras (para fazer ainda outras). Ordenar é contar. Desde o início a Química contou com números pequenos. Os Gregos reduziram tudo a quatro elementos e a quatro propriedades, mais os amores e ódios entre eles. Como diziam os pitagóricos, "Avancem do um até ao quatro e surge o dez, a mãe primordial de todas as coisas". De facto, $1+2+3+4=10$, tantos quantos os dedos das duas mãos. A Química moderna começa com a redefinição do conceito de elemento e a sua associação ao átomo. No final do século XVIII e princípio do século XIX percebeu-se que os elementos se combinavam na proporção de números inteiros e pequenos. Por exemplo, a ferrugem (óxido férrico) são três partes de oxigénio e duas de ferro. Daí à teoria atómica (de Dalton) foi um passo. Entretanto percebia-se que a Química da vida (plantas e animais) estava ligada ao carbono (e ao hidrogénio, oxigénio, nitrogénio, etc). A Química Inorgânica era mais difícil de sistematizar. Até que surgiu uma espécie de calmuque russo, com grandes qualidades pedagógicas e a precisar de ganhar dinheiro. Era (e seria sempre) também um homem de amores fortes. Escreveu um livro - o melhor livro de Química de todos os tempos? - e houve luz, com a Tabela Periódica. Dalton e Mendeleev puseram a Química na ordem, e hoje é a Química quem mais ordena. Pelo meio, houve várias revoluções...
\end{abstract}

\section{No Princípio Era o Quatro}

A Química começou com um número: quatro! Como diziam os pitagóricos, ”Avancem do um até ao quatro e surge o dez, a mãe primordial de todas as coisas”. De facto, $1+2+3+4=10$, tantos quantos os dedos das duas mãos. Há os quatro elementos dos gregos, os quatro pontos cardeais, os quatro temperamentos (sanguíneo, fleumático, melancólico e colérico), os quatro humores (sangue, bílis amarela, bílis preta e fleuma), as quatro estações do ano, as quatro partes do dia (manhã, tarde, crepúsculo e noite), os quatro cantos do quadrado e do rectângulo, os quatro continentes (até à descoberta da Austrália no princípio do século XVII). E mais: os quatro rios do jardim do Paraíso (Pichon, Gihon, Tigre e Eufrates), os quatro Evangelhos, os quatro cavaleiros do Apocalipse, os quatro arcanjos do Islão (Gabriel, Miguel, Asrael, Rafael), os quatro reis celestes (Budismo), as quatro verdades nobres do Budismo (o sofrimento, a sua causa, o seu fim, e o caminho para o fim), as quatro bestas celestes da China (tartaruga, tigre branco, pássaro vermelho, dragão), os quatro naipes do baralho de cartas, as quatro operações da aritmética, os quatro estados da matéria (sólido, líquido, gás e plasma), as quatro fases da Lua, os quatro satélites jovianos descobertos por Galileo (Io, Ganimedes, Calisto e Europa), as quatro asas dos insectos, os quatro grupos sanguíneos (A, B, AB e O ou zero), as quatro valências do carbono, as quatro bases nitrogenadas do ADN, as quatro coordenadas do espaço-tempo, as quatro forças fundamentais (electromagnética, gravitação, forte e fraca), as quatro leis da termodinâmica,

\footnotetext{
* Conferência proferida no Auditório 2 da Fundação Calouste Gulbenkian, em Lisboa, a 19 de Outubro de 2011, no âmbito das comemorações do Ano Internacional da Química.
}

os quatro números quânticos (principal, azimutal, magnético e spin), os quatro instrumentos dum quarteto de cordas, os quatro andamentos da sinfonia, os quatro versos de uma quadra popular, as quatro rodas dos carros, as palavras de quatro letras (em inglês, que em português têm cinco...). Para os jovens da minha geração, os quatro Beatles. Chega?

O cardinal cinco também é importante. Os cinco dedos da mão. Os cinco poliedros regulares. As cinco máquinas elementares dos Gregos (roda e eixo, alavanca, cunha, roldana e parafuso). Os quatro continentes que afinal eram cinco. Os quatro elementos mais o éter ou a quintessência. Os cinco livros do Torah (Génesis, Exodus, Leviticus, Números e Deuteronomia). As cinco orações diárias a Alá. As cinco forças (desdobrando a electromagnética). O pentágono da secção áurea e a quinta perfeita, símbolos duma qualidade estética na pintura, arquitectura e música.

A Química procura responder a uma curiosidade universal: de que é que são feitas as coisas? Os Gregos, que sabiam tudo, deram-nos a primeira teoria química (elementos) e o primeiro modelo físico (átomos). Como tal, a Química começou mesmo com os quatro elementos de Empédocles de Agrigento (século V a.C.) - o tal que julgava que era imortal e foi vítima do mais agressivo de todos os elementos, o fogo. Precipitou-se na cratera do vulcão do Monte Etna e nunca mais foi visto. Segundo Empédocles, os elementos andariam associados aos deuses - o ar a Zeus, a terra a Hera, o fogo a Hades (Inferno) e a água a Nestis (ou Perséfona) - e as respectivas interacções seriam reguladas pelas forças do amor e do conflito (Vénus e Marte, ou seja, amor e ódio, atracção e repulsão). Um século depois de Empédocles, Aristóteles (século IV a.C.) introduziu um quinto elemento - o éter ou quintessência, que enche o espaço sideral, ficando assim completa a correspondência entre 
os elementos e os poliedros platónicos regulares: o fogo representado pelo tetraedro, a terra pelo cubo, o ar pelo octaedro, a água pelo icosaedro e o éter pelo dodecaedro. A propósito: a hipótese do ‘éter’ daria lugar, vinte e três séculos depois, à teoria da relatividade! O fogo, porém, continuava a ser ainda mais excêntrico e insubstancial do que o éter. A Química é filha do fogo (como será, mais tarde, filha da electricidade e das partículas- $\alpha$, uma reminiscência do éter).

Mais do que substâncias, os elementos eram tomados como qualidades ou propriedades. A Natureza era composta de sólidos, líquidos e gases, isto é, de terras, de águas e de ares. A água líquida pertencia ao elemento água, mas a neve e o gelo eram do domínio da terra. Por outro lado, cada elemento era acompanhado (caracterizado) por duas de quatro características sensoriais: frio ou quente, seco ou húmido. Assim, por exemplo, o ar seria quente e húmido, enquanto a terra seria seca e fria - o que permite representar a tetrassomia ou doutrina dos quatro elementos por um quadrado duplo (Figura 1).

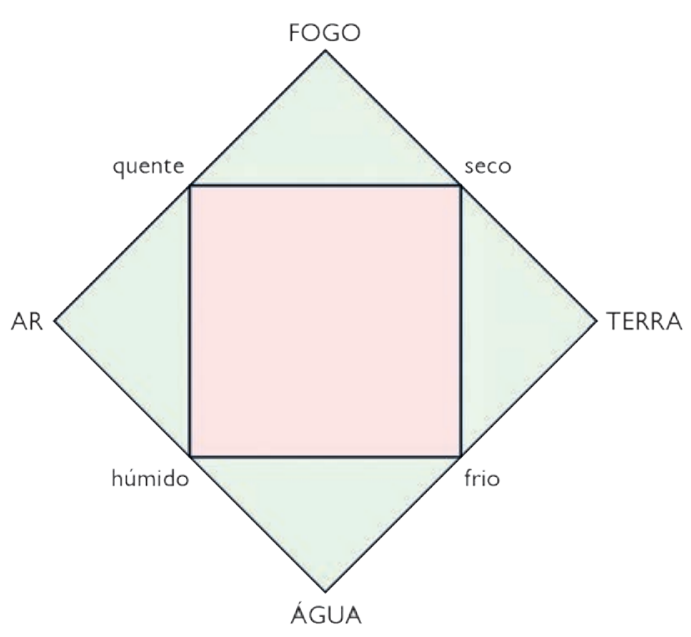

Figura 1 - Os Quatro Elementos

Antes de Empédocles, nos séculos VII e VI a.C., Tales de Mileto (água), Xenófanes de Cólofon (terra), Anaxímenes de Mileto, (ar) e Heraclito de Éfeso (fogo) tinham proposto a água, a terra, o ar e o fogo, respectivamente, como elementos primordiais a que todos os outros se reduziriam. Aristóteles recuperou esta ideia de uma matéria primordial, única e universal, que não seria necessariamente qualquer dos quatro elementos. Se tudo era feito daqueles quatro elementos, nas proporções certas, então seria possível transformar umas coisas nas outras, por exemplo, os metais vis, como o chumbo, em ouro. Parecia impossível; mas seria? Se era viável a uma lagarta metamorfosear-se em crisálida e depois em borboleta, porque não mudar o chumbo em ouro, com a ajuda do mercúrio, elemento alquímico por excelência? (A propósito, sabemos hoje que ouro e mercúrio são elementos adjacentes na Tabela Periódica.) O célebre poema de Ovídio (43 a.C.-ca. 17/18 d.C), Metamorfoses (8 d.C), é exemplar a este respeito: parte da criação do mundo e acaba com a glorificação de Júlio César, através de centenas de narrativas que envolvem a transmutação de deuses e homens em animais, árvores, rios, rochas, etc. Afinal, tudo é feito de mudança, como reiterou Luís de Camões (1524-1580):

Todo o mundo é composto de mudança,
Tomando sempre novas qualidades.

Produzir ouro através da pedra filosofal: foi esta a demanda (que não terá sido inútil...) dos alquimistas, que durou até à segunda metade do século XVII. Robert Boyle (16271691) e Isaac Newton (1643-1727) foram dos últimos e mais ilustres alquimistas. Até que...

\section{Vêm aí As ReVoluções}

[Ouvem-se as passadas da marcha do povo que antecedem “Grândola, Vila Morena”, de José (Zeca) Afonso, a canção que despoletou a Revolução de 25 de Abril de 1974.]

\section{Grândola, vila morena}

Terra da fraternidade

O povo é quem mais ordena

Dentro de ti, ó cidade.

A Química, despoletadora de revoluções, também é filha de revoluções. Chegou a altura de apresentar o Honorável Robert Boyle (1627-1691), filho do súbdito mais rico de Inglaterra e o verdadeiro pai da Química. Estudou no Colégio de Eton mas não frequentou a universidade. Ainda bem! Aos 12 anos (1639), o pai mandou-o fazer o Grand Tour, na companhia do irmão mais velho e de um tutor. A viagem pela Europa, o contacto com outras culturas e outras línguas, a exposição às grandes obras de arte (pintura, arquitectura) e novas técnicas e descobertas científicas (em França, Suíça e Itália) constituíam a melhor educação. Quando regressou (1644), a Inglaterra estava em plena Guerra Civil (1642-1651). Boyle tinha 17 anos, fizera voto de castidade e o pai perdera a maior parte da fortuna apoiando o rei, Charles I (executado em 1649). É nestas condições difíceis que ele inicia os trabalhos científicos que dariam origem aos vários ramos da Química. Toda a gente conhece a Lei de Boyle - o volume de um gás é inversamente proporcional à pressão: o produto $p V$ é constante, a temperatura constante - que marca a matematização (quantificação) de uma classe de produtos, os 'ares', que dominavam então os estudos alquímicos.

Mas a revolução maior vai ao âmago do conceito de elemento. Boyle intuiu que o ar não era um elemento, mas sim composto de três partes: vapores de água e dos animais vivos, emanação do magnetismo terrestre associada à luz (seria o oxigénio), fluido compressível e dilatável, responsável pela mola (elasticidade) do ar (seria o nitrogénio). Repetiu, com uma aboboreira indiana, a experiência do salgueiro realizada por Joan Baptista van Helmont (15771644) no princípio do século XVII, e concluiu, com base nas práticas agrícolas ancestrais, que a água não era o único constituinte das plantas; afirmou que os chamados corpúsculos do ar também contribuíam. Boyle foi o iniciador 
de uma teoria proto-atómica da matéria: o tamanho, forma e angulosidade dos corpúsculos (little bodies) explicariam as propriedades das substâncias.

Boyle fez estudos sobre o peso e a extensão da atmosfera (que seria cada vez mais rarefeita, à medida que se subia em altitude), investigou as propriedades biológicas do ar e a sua importância na respiração (sem saber do oxigénio), estudou fenómenos como a porosidade e o transporte através de membranas, preocupou-se com a produção de baixas temperaturas (fundamento da criogenia), caracterizou os ácidos, álcalis e sais (descobriu um indicador de ácido-base), etc., e foi um dos primeiros a isolar o fósforo a partir da urina (1680). Milagre: obtivera uma substância extraída do corpo humano, produtora de luz, sem queimar. Seria a alma, a pedra filosofal? O que se sabe, é que Boyle esfregou as partes genitais com fósforo e verificou que causava uma inflamação desconfortável. Fica por esclarecer o que teria levado um homem casto a fazer tal experiência... Meus caros: esqueçam a Madame Curie (1867-1934) e o seu segundo Prémio Nobel (1911). O Ano Internacional da Química comemora os 350 anos da publicação de $\boldsymbol{O}$ Químico Céptico (1661), de Robert Boyle - Figura 2.

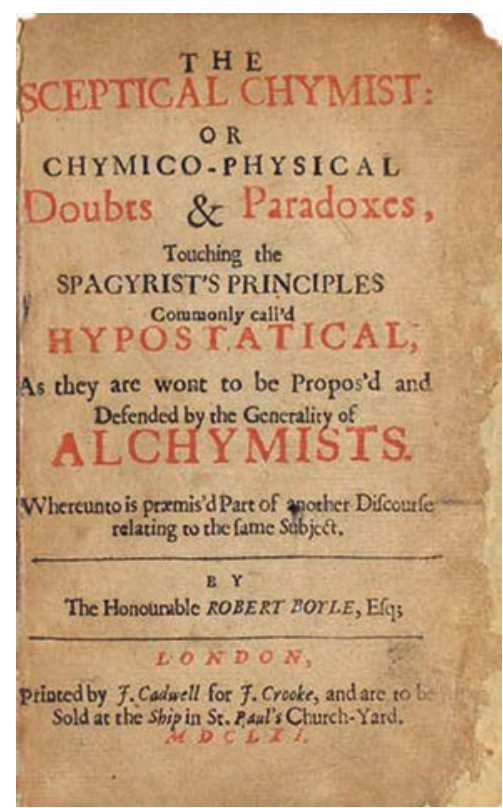

Figura 2 - ROBERT BOYLE, O Químico Céptico, 1661

\section{A Química Dá-se Ares}

Os gases constituíram o fio condutor do desenvolvimento da Química (com a ajuda do fogo e, mais tarde, da electricidade). De facto, é preciso energia para saber de que é que as coisas são feitas. Tal como a curiosidade das crianças as leva a destruir os brinquedos, também os filósofos naturais (cientistas) tentavam destruir e decompor as substâncias para perceber como eram feitas. Sabia-se que era possível extrair ares das terras mais diversas, isto é, que aquecendo sólidos se libertavam gases ('ares factícios'); ou misturando terras com águas, isto é, metais com ácidos. Se o ar não era um elemento, a água também não era (e muito menos a terra, fonte dos materiais mais diversos). A água era, afinal, composta de oxigénio e hidrogénio na bonita proporção de
1 para 2, como demonstrou, em 1784, Henry Cavendish (1731-1810), o descobridor do hidrogénio (1766): 208 medidas de 'ar deflogisticado' (o nome que Joseph Priestley dera ao oxigénio, 1774) combinavam-se com 423 medidas de 'ar inflamável' (o nome que Cavendish dera ao hidrogénio) para formar água. A razão é 2,03. Notável, para a época, tanto mais que Cavendish era um praticante da chamada investigação de "cordel e lata”, embora muito precisa. Era o químico modesto e tímido (embora fosse muito rico).

No final do século XVIII, a Química andava nos ares, em mais do que um sentido. Ar fixo (dióxido de carbono), ar flogisticado (nitrogénio), ar deflogisticado (oxigénio), ar inflamável (hidrogénio), ar ácido (cloreto de hidrogénio), ar alcalino (amoníaco), ar dos pântanos (metano), os vários óxidos de nitrogénio, etc. E havia químicos que "se davam ares”, como Benjamin Franklin (1706-1790) - pai-fundador da América - dizia do seu amigo Joseph Priestley (17331804). E era no ar que estava a chave que permitiu o desenvolvimento espectacular da Química no final do século XVIII: o ar deflogisticado ou oxigénio. Quando Antoine Lavoisier (1743-1794) percebeu que o oxigénio, preparado por Priestley por decomposição do óxido mercúrico, HgO, existia naturalmente no ar, e qual o seu papel nas combustões, nomeadamente na respiração, a Química entrou na maioridade. Não era necessário introduzir artifícios como a postulação dum flogisto negativo para explicar porque é que um metal calcinado aumentava de peso (em vez de o perder). A combustão é uma combinação com o oxigénio.

As revoluções também são alimentadas a oxigénio. Jean-Paul Marat (1743-1793) misturou tudo - fogo, luz e electricidade - e inventou um 'fluido ígneo' que acreditava ter isolado. Quando Lavoisier desmontou e desacreditou as Investigações físicas sobre o fogo (1779) de Marat, arranjou um inimigo figadal para a vida, que muito contribuiria para a sua condenação e morte. (Lavoisier foi guilhotinado em 1794.) Do outro lado da Mancha, o pastor Priestley, apoiante da Revolução Francesa e da independência da América, veria a sua casa, laboratório e capela saqueadas e destruídas pela populaça a 14 de Julho de 1791, precisamente quando se comemoravam dois anos sobre a Revolução (Figura 3). Pouco tempo depois, Priestley emigrava para a América, onde morreu em 1804.

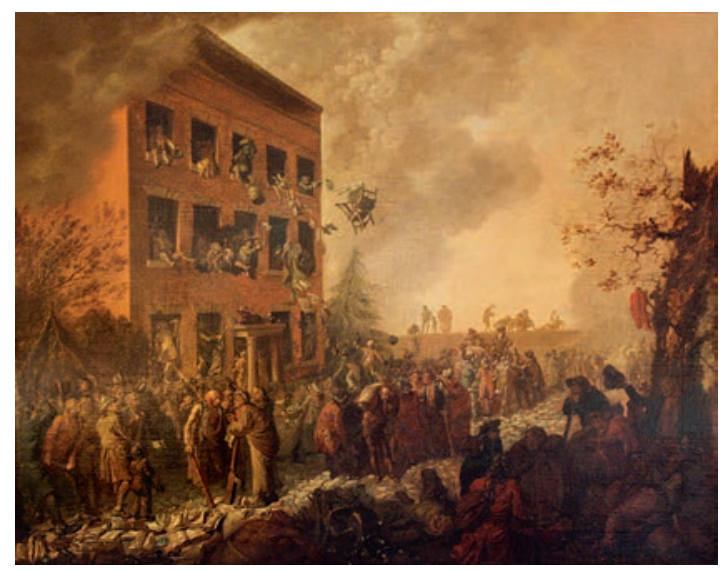

Figura 3 - JOHANN ECKSTEIN, Multidão saqueando e incendiando a casa de Priestley em Birmingham, 14 de Julho de 1791 
A memória de tão nefasto acontecimento está em Portugal. Uma tetraneta de Priestley, a escritora e jornalista Susan Priestley Lowndes (1907-1993), casou em 1938 com o jornalista português Luiz Marques (1898-1976) e veio para Portugal. Com ela veio o quadro de Johann Eckstein (17361817) representando a destruição da casa de Priestley, um incidente que o pintor testemunhou presencialmente. Veio também mobiliário pertencente a Joseph Priestley e vários objectos pessoais, entre os quais o tankard de prata por onde bebia cerveja! Aproveito esta oportunidade para homenagear a memória de Paulo Lowndes Marques (19412011), filho de Susan e Luiz, recentemente desaparecido; foi ele quem, muito generosamente, me proporcionou estas recordações.

\section{Química PItagórica}

À medida que se iam decompondo as substâncias (para perceber de que é que elas eram feitas), ou criando novas substâncias à custa de outras, já existentes, descobriu-se que havia relações quantitativas interessantes (universais) entre os vários componentes. Por exemplo, Joseph-Louis Proust (1754-1826) enunciou a sua lei das proporções definidas em 1799: “somos forçados a reconhecer que há, na Natureza, uma mão invisível que se serve duma balança para formar os compostos”. Em 1803, John Dalton (17661844), um modestíssimo professor primário que comia com talheres de osso (em vez de prata), generalizou-a de uma forma ainda mais bela na sua lei das proporções múltiplas que, uma vez mais, punha em evidência a importância dos números inteiros 1, 2, 3 (mais raramente 4 e 5). Se dois elementos puderem combinar-se entre si para formar mais do que um composto, as massas diferentes de um desses elementos que se combinam com uma massa fixa do outro estão entre si numa razão simples de números inteiros e pequenos. Já era conhecida a variedade de óxidos de nitrogénio (nitroso, nítrico, dióxido, etc), e Dalton investigou os compostos de carbono e hidrogénio, nomeadamente o metano, $\mathrm{CH}_{4}$, e o acetileno, $\mathrm{C}_{2} \mathrm{H}_{2}$ (Figura 4). Ficava por esclarecer o mistério de um sólido (carbono) mais um gás (hidrogénio) dar outro gás. A base de Dalton era Manchester, e por isso está homenageado no Grande Salão da Câmara Municipal, num grande painel pintado por Ford Madox Brown (1821-1893) nos anos 1880, que mostra Dalton a colher metano (gás do fogo) em terrenos pantanosos nos subúrbios da cidade, na companhia de um grupo de alunos, mais ou menos interessados.

Joseph Gay-Lussac (1778-1850) - que favorecia o uso do volume, em vez da massa, na procura de relações quantitativas para os gases - estabeleceria (1805) que os volumes de gases reagentes se combinam também na proporção de números inteiros e pequenos. Recorde-se que ordenação é uma correspondência com a sucessão de números naturais: $1,2,3, \ldots$

Hoje a noção de elemento está associada ao átomo, e foram, de facto, estas constatações aritméticas e pitagóricas que levaram Dalton a formular a sua teoria atómica (por volta de 1805): “os elementos químicos são feitos de parti-

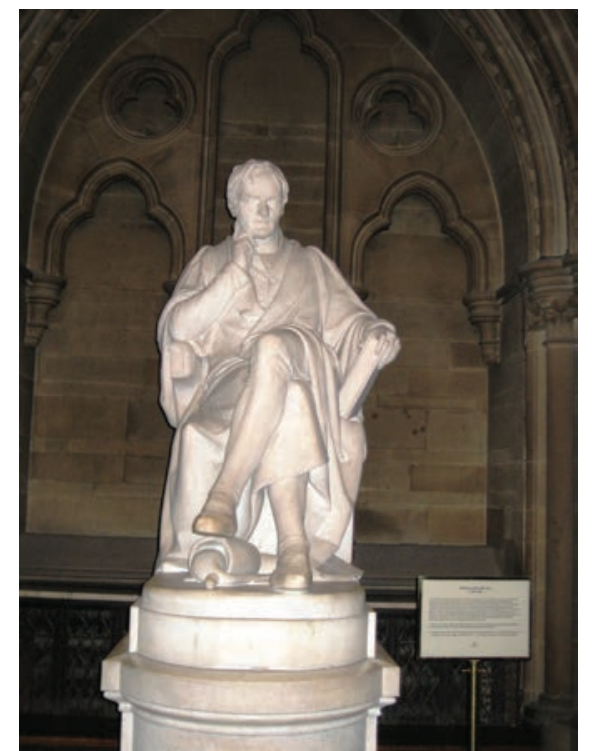

Figura 4 - FRANCIS LEGATT CHANTREY, Monumento a John Dalton, Câmara Municipal de Manchester

culas de matéria minúsculas e indivisíveis, chamadas átomos, que mantêm a sua individualidade em todas as reacções químicas”. A hipótese era demasiado bonita para não excitar a imaginação dos químicos mais audaciosos (embora muitos outros continuassem a negar a existência de átomos durante mais de um século, até se entrar em pleno século XX; achavam que os átomos eram meros artifícios de cálculo, sem base física). O fotoquímico Henry Roscoe (1833-1915), discípulo de Robert Bunsen (1811-1899), afirmava em 1880 que os átomos eram "bocados redondos de madeira inventados pelo Sr. Dalton”. Já em 1900, nove anos antes de receber o Prémio Nobel de Química, Wilhelm Ostwald (1853-1932) escrevia que havia a possibilidade de as substâncias serem compostas de átomos, mas que não havia a certeza.

O conceito de átomo na Química permitiu a diversidade através da simplicidade. Tal como os números são feitos de números primos, as moléculas são feitas de átomos. Veja-se como as permutações de um número finito e pequeno de objectos geram uma multiplicidade enorme de situações! 3 gera 6, 5 gera 120, e 10 (o número de dedos das duas mãos) mais de 3 milhões (3 628 800). Seria preciso esperar 150 anos até encontrar outra situação semelhante com a sequenciação e emparelhamento das bases nitrogenadas, que está na base do código genético. Imaginem-se as possibilidades: as letras do genoma humano (correspondentes às quatro bases, G(uanina), C(itosina), A(denina) e T(imina)) numa sequenciação de três biliões! (As diferenças individuais estão apenas em uma em cada mil.)

Um dos químicos que duvidava da utilidade dos átomos, mas que muito admirava Dalton era Humphry Davy (17781829), professor de Química na Royal Institution de Londres. Convidou logo Dalton para dar um curso de vinte lições, no Inverno de 1804. Davy tinha apenas 25 anos (e Dalton mais 12), e tratou o colega com grande deferência. Ao contrário de Davy, Dalton não tinha grandes qualidades pedagógicas. Davy pediu-lhe para escrever as lições, obrigou-o a ensaios, ouviu-o, e depois deu ele próprio a 
lição para exemplo de Dalton (que aproveitou as dicas de Davy). Assim se ensina e faz pedagogia!

Entre os mais entusiastas pela teoria atómica, estava o sueco Jöns Berzelius (1779-1848), um dos mais notáveis e importantes químicos de todos os tempos (pelo menos tão importante e omnisciente como Lavoisier). Berzelius, que se correspondia com Davy, pediu ansiosamente a este para lhe arranjar um exemplar do famoso livro de Dalton, Um Novo Sistema de Filosofia Química (1808). Quando, finalmente, o livro lhe chegou às mãos, ficou desapontado. Não só Dalton tratava a teoria atómica quase de passagem, como as ideias eram baseadas em análises muito pouco precisas da composição de compostos. Um ponto de discórdia assentava na simbologia (Guyton de Morveau, Lavoisier e outros químicos franceses já tinham tratado da nomenclatura em 1787). Dalton representara os átomos dos elementos por bolinhas de várias espécies: abertas, com centro, cheias, com um traço, com dois traços, etc.

Berzelius propôs letras e, no caso dos átomos compostos, índices correspondendo às proporções de combinação. A Química começava a entrar na ordem: adquiria uma gramática e tornava-se tão fácil de ler como qualquer língua estrangeira. Dalton não gostou: com letras e índices ou expoentes, parecia-lhe que a Química estava escrita em hebraico!

\section{Cabeças No Ar}

Pensar nos gases é pensar no ar, e pensar no ar é pensar no céu. É na Física e Química dos gases que a ciência intersecta a religião. Uma das consequências foi o avanço da meteorologia. Não será um acaso o facto de Dalton ter sido um quase exacto contemporâneo do farmacêutico Luke Howard (1772-1864) - este era apenas seis anos mais novo - o homem que classificou e baptizou os vários tipos de nuvens (cumulus, cirrus, stratus, etc.) no seu Ensaio sobre a modificação das nuvens (1803). Tal como o grande poeta William Wordsworth (1770-1850), Dalton era oriundo do Distrito dos Lagos - onde o tempo (meteorológico) domina as conversas. Não admira: a presença da água e das montanhas provoca uma grande variabilidade de condições atmosféricas - ventos, chuvas e neblinas. Há, de facto, razões específicas para pôr os ingleses a falar do tempo. Fica, pois, explicada a verdadeira obsessão de Dalton com as observações meteorológicas, ocupação de toda uma vida. O primeiro livro que publicou foram as Observações $\boldsymbol{e}$ Ensaios Meteorológicos (1793), e o último trabalho, Da queda da chuva, etc., etc., em Manchester durante 50 anos (1844). Entre eles ficaram registadas mais de 200000 observações meteorológicas!

A questão fundamental que se punha em relação ao ar era saber se era um composto ou uma mistura. Por um lado, a proporção de uma parte de oxigénio para quatro partes de nitrogénio parecia indicar a formação de um composto, $\mathrm{ON}_{4}$ : por outro lado, a variação da composição com a altitude apontava para uma simples mistura. E no ar encontrava-se vapor de água, dióxido de carbono, etc. Dalton percebeu que o ar era uma mistura de gases. Daqui até ao conceito de pressão parcial - a pressão que o componente gasoso duma mistura exerceria se ocupasse todo o volume da mistura - foi um passo. Aqui está uma maneira simples de exprimir a composição de uma mistura gasosa: a soma das pressões parciais de todos os componentes reproduz a pressão total da mistura gasosa.

Com a Revolução Industrial, o centro do saber científico e técnico mudara dos centros universitários para a província. Oxford desprezara as ciências. Iam longe, praticamente esquecidos, os tempos de Boyle! Em Cambridge, o cientista mais activo seria o irascível professor lucasiano de matemática Charles Babbage (1791-1871), inventor da chamada máquina das diferenças - o primeiro computador. Denunciara o estado das coisas nas Reflexões sobre o Declínio da Ciência em Inglaterra e sobre Algumas das Suas Causas (1830) e escandalizava-se com o facto de "um génio, como o Sr. Dalton, se ter de dedicar à escravidão da instrução primária” para ganhar a vida. Londres enredara-se na política e o parlamento ignorava a ciência.

Dalton conseguira um lugar de professor no New College - uma academia dissidente com uma excelente biblioteca - e mudara-se para Manchester em 1793, aos 27 anos. Aí viveu mais de 50 anos. O seu refúgio era a Sociedade Literária e Filosófica, mais conhecida como Lit \& Phil, fundada em 1781. Na segunda metade do século XVIII, Manchester tornara-se numa das grandes metrópoles industriais da Inglaterra, isto é, do mundo. Na base da sua riqueza económica estavam a cerveja e os têxteis. Em 50 anos, a população mais do que quadruplicara. Manchester foi uma das primeiras cidades (1803) a usar a iluminação a gás. (Londres só o faria em 1807.) Na ciência e na técnica, Manchester era um farol (como fora Edimburgo umas décadas antes). Porém, não há bela sem senão, e o senão, aqui, era a poluição, visível nas centenas de chaminés. Quando o químico Justus Liebig (1803-1873) visitou a cidade em 1837, comparou-a a um inferno! (Professor na Universidade de Giessen, Liebig estabeleceria aí uma das primeiras e mais importantes escolas de Química, principalmente no domínio da Química Orgânica.)

\section{ESQUERDA E DIREITA}

O filósofo e empresário alemão Friedrich Engels (18201895) visitou Manchester várias vezes (o pai fundara lá uma fábrica de têxteis) e aproveitou para estudar a condição da classe operária em Inglaterra. O país fora pioneiro nos recenseamentos, inquéritos e estatísticas - aquilo a que hoje chamamos bases de dados - o que lhe facilitou a investigação sociológica. O resultado foi o revolucionário $A$ Condição da Classe Trabalhadora em Inglaterra (1845). Três anos depois, Engels assinava, com Karl Marx (18181883), o Manifesto do Partido Comunista. Engels analisou a vida em grandes cidades como Manchester e Londres, onde "o homem pode deambular horas a fio, sem alcançar o princípio do fim, sem encontrar o mais pequeno indício que o leve a pensar que há campo aberto ao seu alcance”. 
É esta a visão que Gustave Doré (1832-1883) nos deixou nas ilustrações que fez para Londres - Uma Peregrinação (1872), uma perceptiva publicação do jornalista inglês Blanchard Jerrold (1826-1884). Na labuta diária, de casa para o trabalho e do trabalho para casa, as pessoas passavam umas pelas outras como se não tivessem nada em comum. Nas palavras de Engels, "A dissolução da humanidade em mónadas, nas quais cada uma vive segundo um princípio à parte, este mundo de átomos, foi aqui levado ao seu limite máximo”. (O itálico é meu.) Para Engels, as pessoas não eram átomos, tal como hoje dizemos que as pessoas não são números. Mais de um século depois, Margaret Thatcher (1925-2013), primeira-ministra britânica, proclamaria que o que não existe é a sociedade: "there is no such thing as society. There are individual men and women, and there are families”. (A sociedade não existe. Há indivíduos, homens e mulheres, e há famílias.) São as diferenças entre a esquerda e a direita (políticas).

O curioso é que também existe, na Química, uma esquerda e uma direita, como mostrou Louis Pasteur (1822-1895), em 1847. Conheciam-se (1820) duas formas de ácido tartárico (e de tartaratos), quimicamente idênticas - uma opticamente activa (dextrógira) e a outra inactiva (a que Gay-Lussac deu o nome de ácido racémico). (Em Química, o qualificativo de 'opticamente activo' significa que a substância tem a propriedade de fazer rodar o plano de polarização da luz.) O jovem Pasteur examinou os cristais de ácido racémico ao microscópio e verificou que havia cristais esquerdos e direitos (quanto à orientação relativa das faces); separou-os com uma pinça, e mostrou que a solução aquosa dos cristais de um tipo era dextrógira (fazia rodar o plano de polarização da luz para a direita), e que a solução dos cristais do outro tipo era levógira (fazia rodar o plano de polarização da luz para a esquerda). Percebia-se então porque uma mistura, em partes iguais, dos dois tipos de cristais (ácido racémico) era opticamente inactiva.

Pasteur teve muita sorte. De facto, são raríssimos os casos em que uma mistura de moléculas esquerdas e direitas se separa espontaneamente em cristais que contêm apenas moléculas esquerdas e outros que contêm apenas moléculas direitas. Os casos conhecidos contam-se quase pelos dedos de uma mão... Por outro lado, no caso dos tartaratos, tal separação ocorre apenas num intervalo estreito de temperatura. Se Pasteur tivesse realizado a experiência no Verão, com temperaturas no laboratório de trinta e tal graus centígrados, não teria conseguido resolver o problema! O responsável por tais diferenças - esquerda e direita - é uma das maravilhas da química, tão bela como as nossas duas mãos (ou a Vénus de Milo): o átomo de carbono assimétrico. E mais não digo...

\section{As FAmÍLIAS}

Compreender é relacionar e ordenar. As coisas começaram a tornar-se interessantes quando Davy percebeu que havia semelhanças entre elementos diferentes: o potássio e o sódio (que ele isolara e descobrira); o iodo com o cloro (e, mais tarde, o bromo). Halogéneo - que vem do Grego para sal ou mar - foi também um nome dado ao cloro. E verifica-se aqui uma coisa de espantar: uma família de elementos - a única, aliás - com elementos nos três estados da matéria, em condições normais: cloro (gasoso), bromo (líquido), iodo (sólido). Para os Gregos seria o mesmo que dizer que o ar, a água e a terra pertenciam todos à mesma família!

Multiplicaram-se as famílias: metais alcalinos (lítio, sódio e potássio), metais alcalino-terrosos (magnésio, cálcio, estrôncio e bário), halogéneos, do oxigénio (com o enxofre e o selénio), do nitrogénio (com o fósforo, o arsénio, o antimónio e o bismuto). Esta última família, aliás, também é bastante curiosa: começa com um gás $(\mathrm{N})$, continua com um não-metal (P), dois metalóides (As, Sb) e termina num metal (Bi). Seguiram-se as regularidades maravilhosas e harmónicas. Johann Döbereiner (1780-1849), professor da Universidade de Jena e amigo de Goethe (1749-1832), verificou (1829) que a massa atómica do potássio era a média aritmética das massas atómicas do lítio e do sódio e que o mesmo acontecia com a massa atómica do estrôncio em relação ao cálcio e ao bário, ou com o bromo em relação ao cloro e ao iodo. São as tríades de Döbereiner. Depois surgiu a musicalidade da Lei das Oitavas, descoberta pelo inglês John Newlands (1837-1898), em 1863: arrumando (ordenando) os elementos por ordem de massa atómica, constata-se que oito elementos separam o lítio (3) do sódio (11) e este do potássio (19), ou o néon do árgon, ou o oxigénio do enxofre, ou o nitrogénio do fósforo, etc. Dó, ré, mi, fá sol, lá, si, dó. Em vez da música-física das esferas de Johannes Kepler (1571-1630), haveria a música-química dos elementos.

Entretanto (1862) o geólogo francês Alexandre-Emile de Chancourtois (1820-1886), habituado a planear mapas, inscreveu vinte e quatro elementos ao longo de uma hélice cilíndrica (com uma circunferência de base de dezasseis unidades, a massa atómica do oxigénio) e constatou o alinhamento vertical de elementos da mesma família (Figura 5). Conclusão: “as propriedades dos elementos são as propriedades dos números”. Eis a primeira tabela periódica, chamada parafuso telúrico (porque o telúrio, elemento da família do oxigénio, aparecia a meio da tabela).

O artigo foi publicado nos Comptes Rendus (da Academia das Ciências de Paris), mas sem a tabela, e ninguém percebeu. Alemanha, Inglaterra, França; um, dois, três, quatro, etc. químicos intuindo o mesmo. Quando estas coisas acontecem - neste caso, a constatação de regularidades na distribuição dos elementos - é sinal de que algo importante anda no ar. (Passou-se o mesmo com a descoberta do oxigénio, um pouco por todo o lado: Suécia, Inglaterra, França.) Mesmo assim, a evidência daquelas regularidades (periodicidade) foi recebida com indiferença, troça e, até, hostilidade. Para muitos, a massa (ou o volume) atómicos eram apenas uma etiqueta, tão significativa como o nome do elemento. Encontrar tendências ordenando os elementos por massa atómica era, apenas, uma curiosa - mas irrelevante coincidência. Até que... 


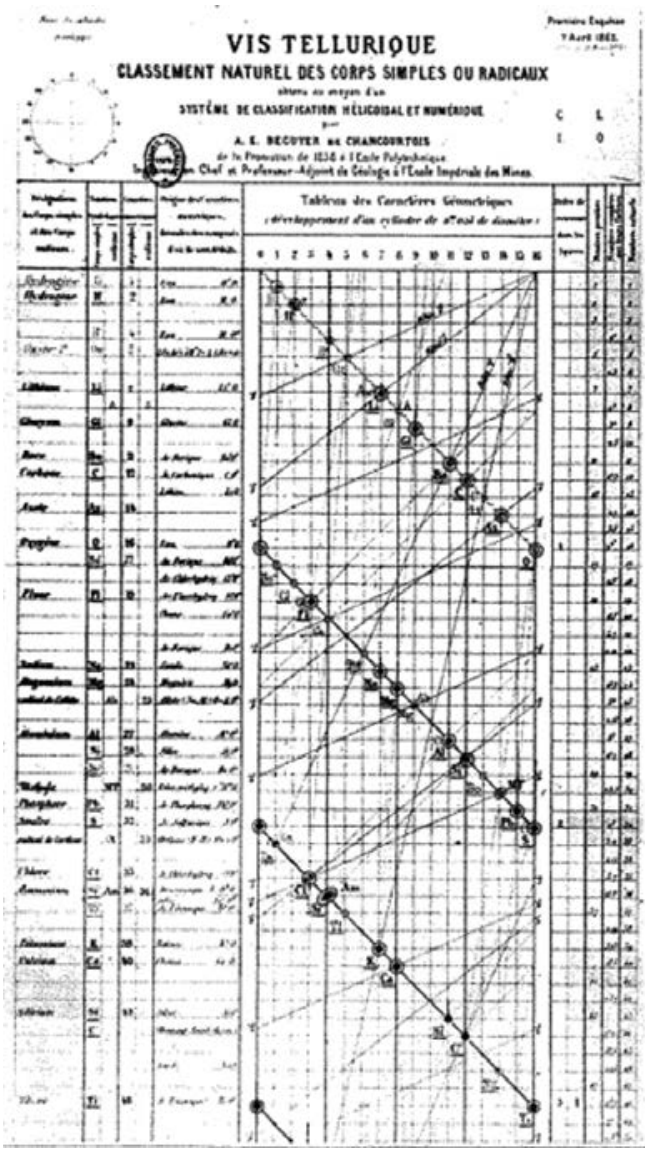

Figura 5 - O parafuso telúrico de Chancourtois

\section{A Saga de Mendeleev}

Chegou a vez de Dmitri Mendeleev (1834-1907), o grande herói da Química russa, proponente da moderna Tabela Periódica dos elementos. A primeira coisa a assinalar é que esta Tabela resultou de um esforço pedagógico e da necessidade de escrever um livro de texto bom, para ganhar dinheiro. Mendeleev aproveitou a oportunidade para arrumar a Química, tal como o Czar Aleksandr II estava a arrumar a Rússia com as suas Grandes Reformas (económicas, sociais e políticas) nos anos 1860 e 1870 . Emancipação dos servos, estatuto universitário, conselhos rurais, reforma do sistema judicial e da censura, autonomia autárquica - aquilo a que chamamos hoje reformas estruturais - houve de tudo, e foi assim que a Rússia começou a acertar os passos com a Europa Ocidental. É preciso acrescentar que Mendeleev tinha tudo contra si, mas triunfou. Lembro-me muito dele nos tempos que correm.

Mendeleev tivera um começo de vida difícil: nascera na Sibéria - o cu de Judas - no seio de uma família modesta; o pai cegara quando Dmitri tinha meses; ficou órfão de pai aos 13 anos; a mãe teve de se empregar para sustentar os catorze filhos (ou seriam dezassete?), mas perdeu o emprego quando a fábrica onde trabalhava ardeu; apercebendo-se do talento do filho mais novo, Dmitri, quis à viva força matriculá-lo na universidade. A mais próxima era em Moscovo, a mais de 2000 km de distância, sem estradas nem caminho-de-ferro. Foram para Moscovo à boleia, de carroça ou carruagem e a pé. Meses de viagem. Quando chega- ram, foi-lhes dito que não havia quota para estudantes da Sibéria. Mais $650 \mathrm{~km}$ de trajecto até São Petersburgo. Aí sim, conseguiu matricular Dmitri - então com dezasseis anos - no Instituto Pedagógico. Poucos meses depois, Maria Dmitrievna Mendeleeva morria tuberculosa. Na hora da morte, aconselhou o filho: "Evita as ilusões, insiste não nas palavras mas no trabalho. Procura pacientemente a verdade científica e divina.”

Dmitri nunca mais a esqueceu - exemplo vivo de um inabalável amor filial. Em 1887, 37 anos após a morte da mãe, dedicou-lhe um dos seus trabalhos mais importantes: "Investigações das soluções aquosas segundo o seu peso específico" (1887), onde abordava o problema das ligações químicas em solução. As palavras escolhidas são significativas: "Este trabalho é dedicado à memória de uma Mãe pelo seu filho mais novo. [Uma Mãe que] ensinou pelo exemplo, corrigiu com amor, e que, com o desejo de o entregar à ciência, abandonou com ele a Sibéria, gastando assim as suas últimas forças e recursos”.

No Instituto Pedagógico de São Petersburgo, Mendeleev revelou-se o melhor aluno da turma, com direito a uma Medalha de Ouro. Mas as dificuldades não tinham acabado: após a conclusão do curso, foi-lhe diagnosticada uma tuberculose, com expectativa de vida de apenas alguns meses. Não desistiu. Procurou alívio no clima ameno da Crimeia, e arranjou um lugar de professor de liceu em Odessa. O problema era a Guerra da Crimeia, literalmente ao pé da porta. Não perdeu tempo, e aproveitou para escrever a tese de mestrado. A boa nova é que, afinal, não estava tuberculoso: o primeiro diagnóstico revelara-se errado! Voltou para São Petersburgo para defender a tese, e em 1859 obteve uma bolsa do governo para especialização no estrangeiro.

Para um russo, o destino óbvio era Heidelberg, onde havia já uma distinta colónia de intelectuais russos; dez por cento dos estudantes universitários provinham da Rússia. Pelo caminho visitou, em Paris, os grandes químicos franceses, e conheceu Liebig em Munique. Em Heidelberg, pontificavam, na Química e na Física, Robert Bunsen (1811-1899), Gustav Kirchhoff (1824-1887) e Emil Erlenmeyer (18251909). O amigo Aleksandr Borodine (1833-1887), que se distinguiria igualmente como compositor, escolheu Erlenmeyer; Mendeleev optou pelos laboratórios de Bunsen e Kirchhoff (que achou deficientes e onde pouco aprendeu). Como dois amigos, Mendeleev e Borodine viajaram juntos pela Europa (Itália) e participaram na famosa (e primeira!) Conferência Internacional de Química, em Karlsruhe (1860). Em 1861, Mendeleev estava de regresso à Rússia: o objectivo, agora, era o doutoramento. Para ganhar algum dinheiro, escreveu e publicou Química Orgânica (1861), um livro de texto muito elogiado por Nikolai Zinine (18121880) - o melhor químico russo da época - e que seria premiado pela Academia de Ciências.

Sob pressão duma das irmãs, em 1863 Dmitri sucumbiu a um casamento arranjado (e infeliz), que produziu dois filhos. Continuava a preparar a tese de doutoramento e a dar aulas em várias instituições (escola militar, instituto técni- 
co). Uma vez doutorado (1865), foi nomeado professor adjunto da Universidade de S. Petersburgo, mas sem direito a salário. Tinha pouco mais de 30 anos, era pai de família e vivia com sérias dificuldades financeiras (Figura 6).

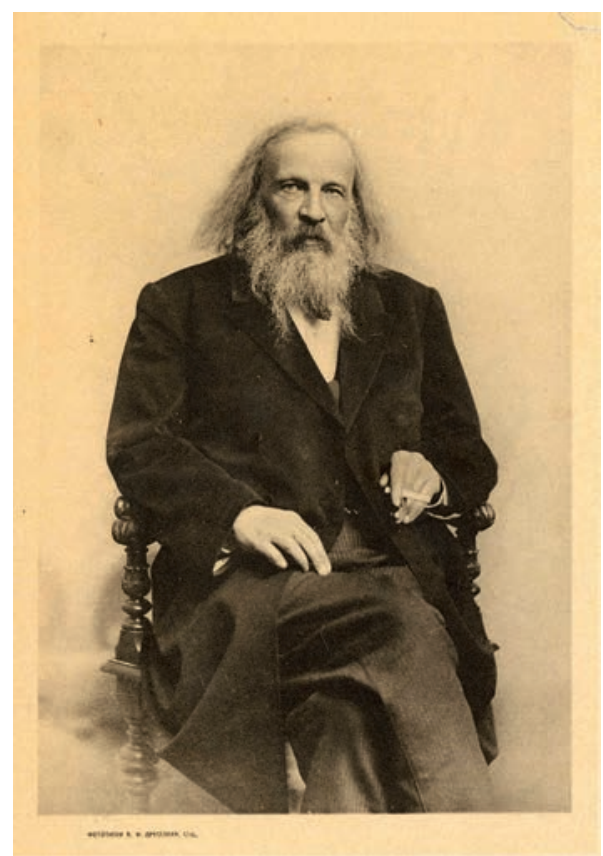

Figura 6 - IVAN KRAMSKOY, Dmitri Mendeleev, 1878

\section{A TABela Periódica}

A solução estava em mais trabalho. Mendeleev precisava de escrever outro livro, desta vez dedicado à Química Inorgânica. Mas enquanto a Química Orgânica lidava com poucos elementos e era relativamente fácil de organizar, a Química Mineral ou Inorgânica lidava com uma variedade estarrecedora de elementos. Como fazer sentido de tudo isto? Mendeleev planeou os seus Princípios de Química em dois volumes: o primeiro, dedicado aos elementos monovalentes (metais alcalinos e halogéneos) e aos elementos básicos da Química Orgânica (carbono, hidrogénio, oxigénio e nitrogénio), apareceu em 1868; o segundo, que tratava dos restantes elementos (então conhecidos), foi publicado em 1870. É, na opinião de muitos - entre eles Oliver Sachs (n. 1933), o médico e professor de neurologia da Universidade de Columbia - o melhor livro de Química jamais publicado.

A história é conhecida. Mendeleev era um grande pedagogo, com uma enorme cultura e múltiplos interesses, que encantava os estudantes. Nos Princípios de Química, quis tornar a Química atraente e lógica. Como ordenar e relacionar os cinquenta e tal elementos do $2 .^{\circ}$ volume? Por outras palavras, como meter a Química na ordem (para que ela, por sua vez, nos impusesse as suas ordens)? Mendeleev procedeu de modo sistemático, coligindo as propriedades dos elementos, nomeadamente a respectiva massa atómica. Como gostava de jogar às paciências, utilizou um baralho de cartas, uma para cada elemento e experimentou vários tipos de ordenações. Em Março de 1869 fez-se luz: sentiu e descobriu, sem margem para dúvidas, que as propriedades dos elementos eram "funções periódicas das suas massas atómicas”.

É verdade: Chancourtois e outros tinham chegado aqui primeiro, mas sem perceberem muito bem o alcance da descoberta. Mendeleev, porém, acreditava na força das suas convicções. Se a ordem (de semelhanças) parecia alterada, é porque a massa atómica estava errada (mal determinada). Daí os pontos de interrogação (?) na sua primeira tabela. Era o caso do berílio (a que se atribuíra massa 14), e que, portanto, aparecia colado ao nitrogénio, o que era um disparate; Mendeleev atribuiu-lhe massa 9 (o que estava certo) e inscreveu-o no grupo do magnésio (alcalino-terrosos), o que fazia quimicamente sentido.

Inverteu ainda as posições do iodo (com massa atómica 126.9) e do telúrio (127.6), mais as do cobalto (58.9) e do níquel (58.7) - o que, dada a proximidade dos valores, seria aceitável - mas duplicou (!) a massa atómica do urânio, causando um verdadeiro escândalo! Até aí, julgava-se que o elemento mais pesado era o bismuto. Não era, de facto, e Mendeleev tinha razão - dos conhecidos, o elemento de maior massa atómica era o urânio. Por algum motivo, os elementos seguintes seriam chamados transuranianos. Foi preciso esperar uns sessenta ou setenta anos até se descobrirem (fabricarem) o neptúnio e o plutónio - este último, sim, o mais pesado dos elementos primordiais.

Mendeleev não se ficou por aqui, e foi mais longe, num rasgo de génio, ao prever a existência de elementos ainda por descobrir. Como e porquê? Porque nas suas famílias de elementos havia buracos ou lacunas. Como não acreditava em saltos na Natureza (o horror ao vácuo?), postulou a existência de novos elementos, baptizou-os e previu-lhes as propriedades (massa atómica, densidade, ponto de fusão, etc.). Por exemplo, a seguir ao alumínio (mesma família) e perto do zinco, haveria um elemento a que deu o nome de $e k a$ -alumínio (do sânscrito eka, para um) - que viria a ser o gálio, descoberto em 1875. Idem para o eka-silício, que seria o germânio (identificado em 1886), e para o eka-manganês ou tecnécio - um metal radioactivo fabricado em 1937 pelo italiano Emilio Segrè (1905-1989). Mas também se enganou: num trabalho escrito em 1902 e publicado em 1904, Uma Concepção Química do Éter, considerou dois elementos mais leves que o hidrogénio, componentes de uma atmosfera interestelar (éter). O mais leve teria uma massa atómica da ordem da centésima milionésima parte da do hidrogénio.

É injusto conhecer Mendeleev apenas através da Tabela Periódica. As suas contribuições para a Química (e para as políticas científicas do Estado) são tão ou mais importantes do que as de Lavoisier. Isomorfismo, capilaridade, ponto crítico, Química das soluções, meteorologia, gaseificação do carvão - eis alguns dos temas e assuntos investigados por Mendeleev. Paladino da agricultura racional, foi também fundador da indústria do petróleo russa, e interessou-se pela indústria do ferro nos Urais. Foi co-fundador da Sociedade Russa de Física e Química (1868) e membro do Gabinete Russo de Pesos e Medidas (responsável pela introdução do sistema métrico, embora a título facultativo). 
Em 1882, Dmitri Mendeleev casou-se pela segunda vez (embora já vivesse em união de facto e tivesse uma filha, Liubov). Tecnicamente era um bígamo, pois não esperara os seis anos legais após o divórcio da primeira mulher. Mas continuava indispensável ao Czar como conselheiro científico. Infelizmente, o Czar reformista, Aleksandr II (18181881), foi assassinado em 1881, e o novo Czar Aleksandr III (1845-1894) revelar-se-ia muito menos liberal. Mesmo assim, quando lhe fizeram notar a situação ilegal de Mendeleev, terá retorquido: "Pois é, ele pode ter duas mulheres, mas eu só tenho um Mendeleev”. Não tardou muito até que o governo começasse a assumir posições reaccionárias e repressivas, tentando travar os ventos do progresso (e até revogando as anteriores reformas liberais). Durante a grave crise estudantil de 1890, Mendeleev participou nas reuniões dos estudantes e defendeu-os resolutamente perante o governo. Ao saber que o ministro se recusara a receber a carta de protesto, demitiu-se da cátedra universitária (embora continuasse as suas pesquisas científicas).

No final do século XIX, Mendeleev atingia o auge da fama, muito considerado em todos os meios científicos e artísticos. Por justiça, devia ter recebido o primeiro Prémio Nobel da Química em 1901 (atribuído a van’t Hoff). Não aconteceu, nem aconteceria nos cinco anos seguintes (morreu em 1907). Na literatura, Lev Tolstoi (1828-1910) teria o mesmo destino. O que poucos valorizam é o facto de Mendeleev se ter distinguido, também, como crítico de arte e ter sido eleito (1894) para a Academia Russa das Artes. Viajava para receber honrarias e doutoramentos honoris causa. Em Londres (1884), William Perkin (1838-1907), o descobridor do corante cor-de-malva (que revolucionou a tinturaria e a indústria química) viu-o como uma criatura extravagante, um verdadeiro calmuque (uma comunidade de budistas da Mongólia que emigraram para a Rússia no século XVII, estabelecendo-se no Baixo Volga). Outra semelhança com Lavoisier: o Salão ou tertúlia dos Mendeleev era frequentado pelos grandes intelectuais e artistas russos: compositores como Borodine ou Modest Mussorgsky (1839-1881), artistas como Ilya Repin (1844-1930), considerado o maior pintor russo (e que, aliás, lhe pintou o retrato, envergando as vestes doutorais da Universidade de Edimburgo). A filha, Liubov Mendeleeva, distinguiu-se como actriz e promotora do bailado russo, e pelas várias paixões que despertou e cultivou: casou com o poeta Aleksandr Blok (1880-1921) e teve um caso tórrido com o escritor Andrei Bely (1880-1934) - os dois maiores expoentes do simbolismo russo. O apelido Mendeleev/Mendeleeva é sinónimo de amor: filial, paternal, conjugal, erótico e profano.

Mas a glória da Química é a Tabela Periódica, que toda a gente devia saber de cor (Figura 7). É o mais belo e admirável Palácio de Memória que conheço. Cada elemento tem o seu número de ordem, $Z$ (o número de electrões, que é também o número de protões do núcleo), e vai do hidrogénio, o elemento do espaço sideral, até ao ununóctio de $Z=118$, nascido e confirmado em 2002, mas ainda não baptizado. Tudo o que existe é feito de átomos, moléculas, substâncias químicas. Esta casa (Auditório 2 da Fundação Calouste Gulbenkian), eu e todos vós - o público; este livro, os seus autores e os respectivos leitores. Aqui, na Tabela, estão os números. Aí, a ler, a ouvir e a pensar (sonhar), estão as pessoas, a sociedade. A Química, essa, está em toda a parte.

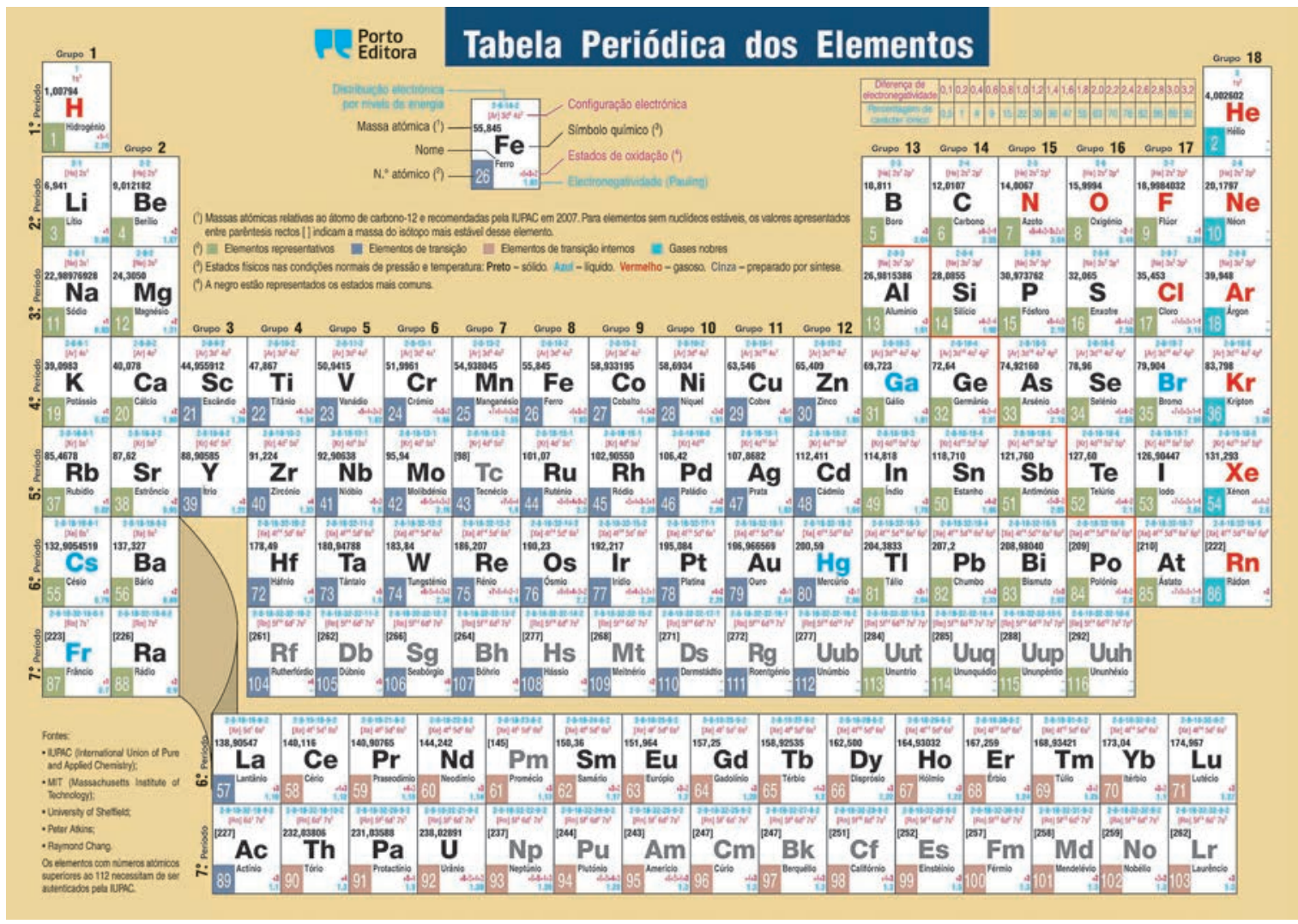

Figura 7 - Tabela Periódica [Porto Editora] 


\section{Antoine-Laurent LAVOISIER}

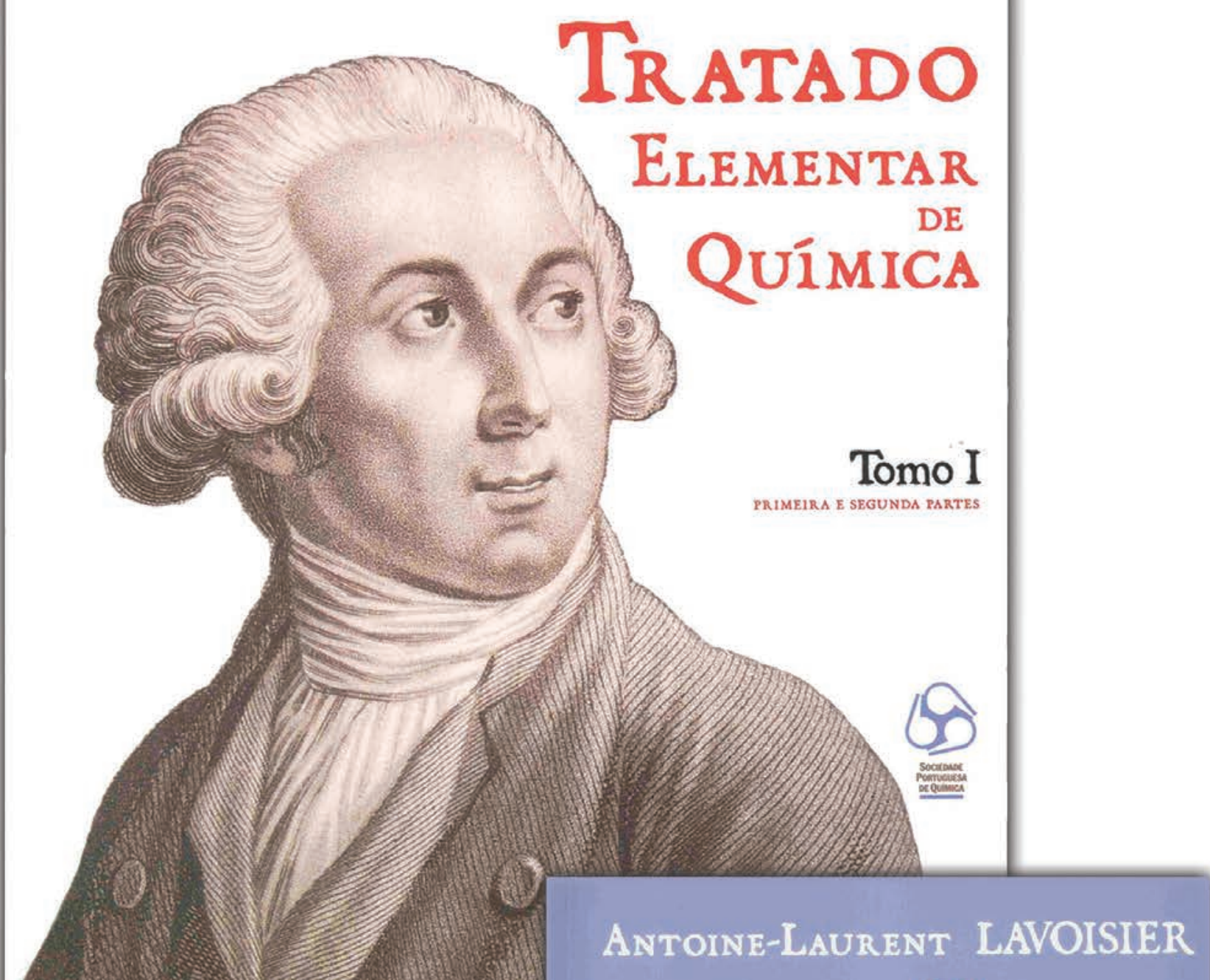

0 "Tratado Elementar de Química» de Antoine-Laurent Lavoisier (1743-1794), publicado em Paris em 1789, é um dos grandes clássicos da Química. Escrito na nova nomenclatura proposta também por Lavoisier, em conjunto com Morveau, Berthollet e Fourcroy, é a primeira obra de química moderna, abandonando-se as inadequadas designações de raizes alquímicas e a desacreditada teoria do flogisto. No tratado, ilustrado pela mulher do autor, Marie-Anne-Pierrette Paulze Lavoisier, formula-se de forma clara a conservação da matéria e define-se elemento químico de forma operacional.

No centenário da fundação da Sociedade Portuguesa de Química, publica-se finalmente uma cuidada tradução portuguesa do "Traité», modernizada e anotada.

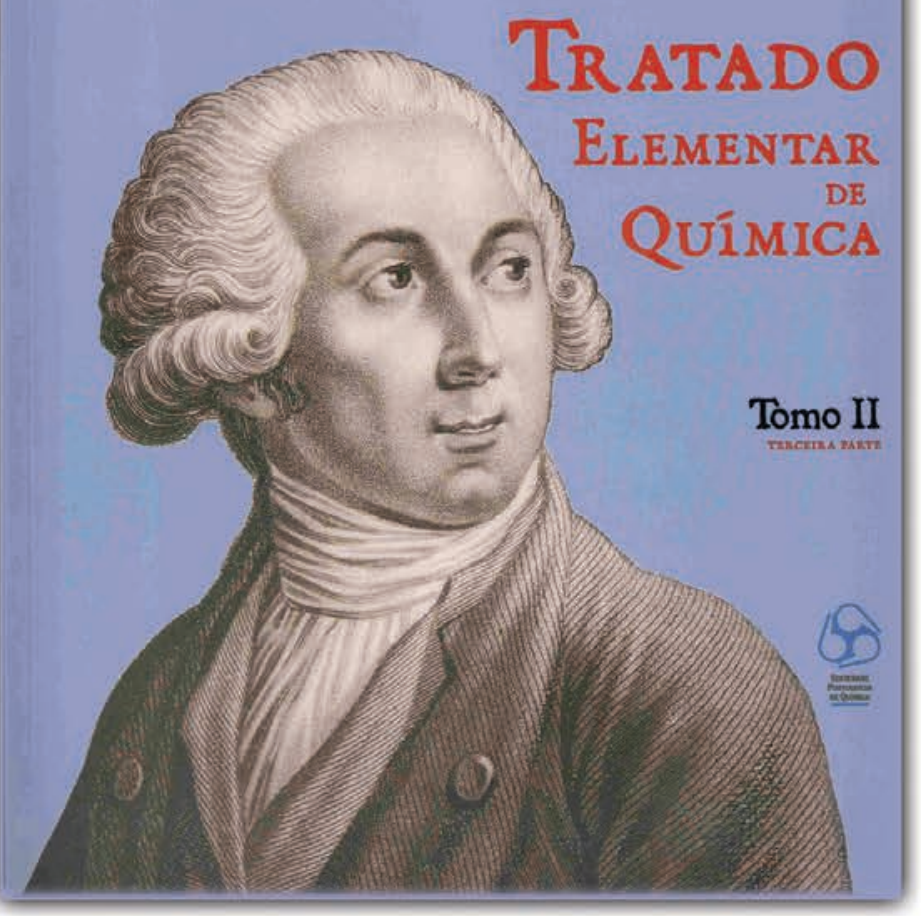

